\title{
Karakteristik Kasus Kekerasan Seksual di Rumah Sakit Tipe A di Jawa Barat dan Sumatera Barat
}

\author{
Noverika Windasari ${ }^{1}$, Yoni Fuadah Syukriani ${ }^{2}$, Sani Tanzilah $^{2}$
}

\begin{abstract}
Abstrak
Kasus kekerasan seksual di Indonesia cukup menonjol di antara berbagai jenis kekerasan terhadap perempuan dan anak. Pengetahuan terkait karakteristik kekerasan seksual sangat penting dalam penanganan kasus kekerasan seksual yang optimal. Tujuan: Mengevaluasi karakteristik kasus kekerasan seksual yang diperiksa di Rumah Sakit Pemerintah tipe A di Jawa Barat dan Sumatera Barat. Metode: Penelitian ini berupa studi deskriptif retrospektif menggunakan data rekam medis seluruh pasien dugaan kasus kekerasan seksual yang diperiksa di RSUP Dr Hasan Sadikin (Bandung) dan RSUP Dr. M. Djamil (Padang) periode 1 Januari 2014 sampai 31 Desember 2018. Hasil: Pasien/korban dugaan kekerasan seksual pada kedua rumah sakit tersebut didominasi oleh perempuan, belum menikah, dengan kelompok usia terbanyak 10-19 tahun. Sebagian besar korban datang ke rumah sakit dalam rentang waktu 1 hari hingga 1 minggu setelah kejadian, dengan jenis kekerasan seksual yang dialami korban terutama adalah penetrasi vagina. Sebagian besar pelaku kekerasan seksual berjumlah satu orang (tunggal) dan dikenal oleh korban, kekerasan seksual terutama terjadi pada siang hari di tempat pribadi. Pada sebagian besar kasus tidak ditemukan tanda-tanda kekerasan pada tubuh korban selain kelainan pada anogenital. Simpulan: Karakteristik kasus kekerasan seksual di Jawa Barat menyerupai karakteristik kasus kekerasan seksual di Sumatera Barat. Perbedaan yang menonjol terletak pada tingkat pendidikan terakhir korban.
\end{abstract}

Kata kunci: kekerasan seksual, karakteristik pasien, rekam medis

\section{Abstract}

Sexual assault in women and children is very prominent, among other abuse. Knowledge related to the characteristics of sexual assault is vital for optimal handling of sexual assault cases. Objectives: To evaluated the characteristics of sexual assault cases in referral hospitals (type A hospital) in West Java and West Sumatera provinces. Methods: This research was a retrospective descriptive study. The samples were patients suspected of being victims of sexual assault, examined from 1 January 2014 to 31 December 2018. Results: The alleged sexual assault victims are dominated by women, unmarried, with the most age groups of 10-19 years. Most victims come to the hospital within a week after the case. The primary type of sexual assault experienced by the victims is vaginal penetration. Most perpetrators were someone who was well known by the victims. The perpetrators prefer to act at noon in a private place. Medical records revealed that in most cases, only signs of violence on the anogenital region, and no trace on other body parts. Conclusion: The characteristic of sexual assault from both provinces are almost similar. The difference that stands out lies in the level of education of victims.

Keywords: sexual assault, patient characteristic, medical record

Affiliasi penulis: ${ }^{1}$ Bagian IImu Kedokteran Forensik dan Medikolegal, Fakultas Kedokteran, Univesitas Andalas, Padang, Indonesia. ${ }^{2}$ Departemen IImu Kedokteran Forensik dan Medikolegal, Fakultas Kedokteran, Universitas Padjadjaran, Bandung, Indonesia. Korespondensi: Noverika Windasari,

Email: windasari@med.unand.ac.id. Telp: 08116663343

\section{PENDAHULUAN}

Kekerasan seksual merupakan setiap perbuatan yang berupa pemaksaan hubungan seksual, dengan cara tidak wajar dan/atau tidak disukai, pemaksaan hubungan seksual dengan orang lain untuk tujuan 
komersial dan/atau tujuan tertentu. ${ }^{1}$ Kekerasan seksual dapat terjadi di mana saja, pada semua rentang umur dan jenis kelamin. Meskipun sebagian besar korban kekerasan seksual adalah perempuan, namun dapat juga terjadi pada laki-laki dan anak-anak (laki-laki maupun perempuan). ${ }^{2}$ Data World Health Organization (WHO) menyebutkan bahwa satu dari lima perempuan mengalami pelecehan seksual atau pemerkosaan oleh pasangan intimnya. ${ }^{3}$ Menurut Kementerian Kesehatan RI, satu dari lima perempuan dan satu dari tiga belas laki-laki melaporkan pernah mengalami kekerasan seksual saat usia anak/remaja. ${ }^{4}$

Kasus kekerasan seksual di Indonesia cukup menonjol di antara berbagai jenis kekerasan terhadap perempuan dan anak. ${ }^{2}$ Komisi Nasional Anti Kekerasan terhadap Perempuan mencatat jumlah kasus kekerasan seksual terhadap perempuan berjumlah 4.475 kasus pada tahun 2014, meningkat menjadi 6.499 kasus pada tahun 2015, kemudian berjumlah 5.785 kasus pada tahun 2016, dan 5.293 kasus pada tahun $2018 .^{5}$ Pada tahun 2019, kasus kekerasan seksual sebanyak 4.898 kasus. ${ }^{6}$ Kekerasan seksual berpotensi menimbulkan pengalaman traumatik yang dapat berdampak bagi korban, baik dari segi mental, fisik, kesehatan reproduksi dan seksual, yang dapat bersifat akut maupun jangka panjang. ${ }^{7}$ Selain itu, kekerasan seksual juga berdampak terhadap beban sosial, diantaranya bertambahnya biaya di sektor kesehatan untuk pengobatan penyakit sekunder korban kekerasan seksual. $^{8}$

Banyaknya jumlah kasus kekerasan seksual di Indonesia membutuhkan penanganan yang tepat, termasuk di bidang kesehatan. Pengetahuan terkait karakteristik kekerasan seksual sangat penting dalam penanganan kasus kekerasan seksual yang optimal. Penelitian ini bertujuan untuk mengetahui bagaimana karakteristik kasus kekerasan seksual yang diperiksa di Rumah Sakit tipe A di Jawa Barat (RSUP. Dr. Hasan Sadikin) dan Sumatera Barat (RSUP Dr. M. Djamil).

\section{METODE}

Penelitian ini berupa studi deskriptif retrospektifmenggunakan data rekam medis seluruh pasien dugaan kasus kekerasan seksual (total sampling) yang diperiksa di Rumah Sakit tipe A di Jawa Barat dan Sumatera Barat, yaitu RSUP. Dr. Hasan Sadikin (Bandung) dan RSUP Dr. M. Djamil (Padang) periode 1 Januari 2014 - 31 Desember 2018, baik yang disertai surat permintaan visum et repertum dari penyidik maupun tidak. Seluruh data dikumpulkan dan diolah menggunakan perangkat lunak Microsoft Excel 2010. Penelitian dilakukan setelah mendapat persetujuan etik dari RSUP Dr. Hasan Sadikin No. LB.02.01/X.6.5/289/2019 dan persetujuan etik dari RSUP Dr. M. Djamil No. 347/KEPK/2019.

\section{HASIL}

Dalam periode lima tahun penelitian, didapatkan total 159 rekam medis kekerasan seksual, yang terdiri dari 58 rekam medis di RSUP Dr Hasan Sadikin dan 101 rekam medis di RSUP Dr M. Djamil. Pasien/ korban dugaan kekerasan seksual pada kedua rumah sakit tersebut didominasi oleh perempuan, yaitu 49 orang $(84,5 \%)$ di RSUP Dr. Hasan Sadikin dan 93 orang (92,1\%) di RSUP Dr. M.Djamil (Gambar 1).

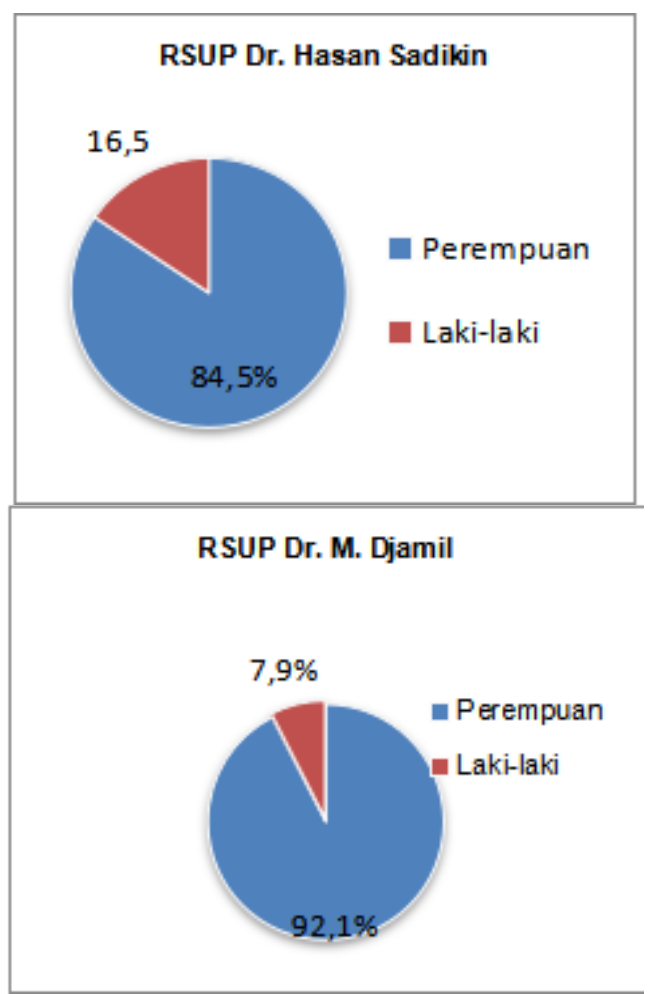

Gambar 1. Korban kekerasan seksual berdasarkan jenis kelamin di RSUP Dr. Hasan Sadikin Bandung dan RSUP Dr. M. Djamil Padang 
Korban kekerasan seksual yang diperiksa di RSUP Dr. Hasan Sadikin dan RSUP Dr. M.Djamil terutama belum menikah, dengan kelompok usia terbanyak 10-19 tahun diikuti kelompok usia 0-9 tahun. Sebagian besar korban datang ke rumah sakit dalam rentang waktu 1 hari hingga 1 minggu setelah kejadian dengan jenis kekerasan seksual yang dialami korban terutama adalah penetrasi vagina.

Sebagian besar pelaku kekerasan seksual berjumlah satu orang (tunggal) dan dikenal oleh korban, kekerasan seksual terutama terjadi pada siang hari di tempat pribadi seperti rumah, kost atau hotel. Sebagian besar korban yang diperiksa pada kedua rumah sakit ini merupakan pelajar/mahasiswa. Terdapat perbedaan tingkat pendidikan terakhir korban, yakitu di RSUP Dr. Hasan Sadikin terutama SMP, sedangkan di RSUP Dr. M. Djamil adalah SD. Korban kekerasan seksual yang mengalami gangguan kejiwaan pascatrauma di RSUP Dr. Hasan Sadikin dan RSUP Dr. M. Djamil masing-masing 32,8\% dan 8,9\%. Hasil pemeriksaan pada kedua rumah sakit tersebut, tidak ditemukan tanda-tanda kekerasan pada tubuh korban selain kelainan pada anogenital. Rincian karakteristik korban kekerasan seksual dapat dilihat pada Tabel 1.

Tabel 1. Karakteristik kasus kekerasan seksual di RSUP Dr. Hasan Sadikin dan RSUP Dr. M. Djamil periode 20142018

\begin{tabular}{|c|c|c|c|c|c|}
\hline & & \multicolumn{4}{|c|}{ Rumah Sakit } \\
\hline \multirow{2}{*}{\multicolumn{2}{|c|}{ Karakteristik }} & \multirow{2}{*}{\multicolumn{2}{|c|}{$\begin{array}{l}\text { RSUP Dr. Hasan } \\
\text { Sadikin }\end{array}$}} & \multirow{2}{*}{\multicolumn{2}{|c|}{$\begin{array}{l}\text { RSUP Dr. M. } \\
\text { Djamil }\end{array}$}} \\
\hline & & & & & \\
\hline & & Jumlah & $\%$ & Jumlah & $\%$ \\
\hline (1) & (2) & (3) & (4) & (5) & (6) \\
\hline \multirow[t]{5}{*}{ Usia } & $0-9$ tahun & 16 & $27.6 \%$ & 25 & $24.8 \%$ \\
\hline & 10-19 tahun & 33 & $56.9 \%$ & 64 & $63.4 \%$ \\
\hline & 20-29 tahun & 6 & $10.3 \%$ & 11 & $10.9 \%$ \\
\hline & 30-39 tahun & 3 & $5.2 \%$ & 0 & $0.0 \%$ \\
\hline & $\geq 40$ tahun & 0 & $0.0 \%$ & 1 & $1.0 \%$ \\
\hline \multirow[t]{7}{*}{ Pendidikan Terakhir } & Belum Sekolah & 0 & $0.0 \%$ & 16 & $15.8 \%$ \\
\hline & TK & 2 & $3.4 \%$ & 3 & $3.0 \%$ \\
\hline & SD & 8 & $13.8 \%$ & 37 & $36.6 \%$ \\
\hline & SMP & 12 & $20.7 \%$ & 19 & $18.8 \%$ \\
\hline & SMA & 8 & $13.8 \%$ & 23 & $22.8 \%$ \\
\hline & Perguruan Tinggi & 1 & $1.7 \%$ & 1 & $1.0 \%$ \\
\hline & $\mathrm{N} / \mathrm{A}$ & 27 & $46.6 \%$ & 2 & $2.0 \%$ \\
\hline \multirow[t]{6}{*}{ Pekerjaan } & PNS & 0 & $0.0 \%$ & 0 & $0.0 \%$ \\
\hline & Wiraswasta & 0 & $0.0 \%$ & 4 & $4.0 \%$ \\
\hline & Buruh & 0 & $0.0 \%$ & 1 & $1.0 \%$ \\
\hline & TidakBekerja & 14 & $24.1 \%$ & 33 & $32.7 \%$ \\
\hline & Pelajar/Mahasiswa & 40 & $69.0 \%$ & 63 & $62.4 \%$ \\
\hline & $\mathrm{N} / \mathrm{A}$ & 4 & $6.9 \%$ & 0 & $0.0 \%$ \\
\hline \multirow[t]{4}{*}{ Status Pernikahan } & Menikah & 7 & $12.1 \%$ & 2 & $2.0 \%$ \\
\hline & Belum Menikah & 51 & $87.9 \%$ & 95 & $94.1 \%$ \\
\hline & Duda/Janda & 0 & $0.0 \%$ & 1 & $1.0 \%$ \\
\hline & $\mathrm{N} / \mathrm{A}$ & 0 & $0.0 \%$ & 3 & $3.0 \%$ \\
\hline Gangguan Kejiwaan & Ada & 19 & $32.8 \%$ & 9 & $8.9 \%$ \\
\hline \multirow[t]{2}{*}{ Pascatrauma } & Tidak ada & 33 & $56.9 \%$ & 71 & $70.3 \%$ \\
\hline & $\mathrm{N} / \mathrm{A}$ & 6 & $10.3 \%$ & 21 & $20.8 \%$ \\
\hline \multirow[t]{3}{*}{ Riwayat Seks Sebelumnya } & Tidak Pernah & 9 & $15.5 \%$ & 35 & $34.7 \%$ \\
\hline & 1 Kali & 2 & $3.4 \%$ & 10 & $9.9 \%$ \\
\hline & Lebih dari 1 kali & 20 & $34.5 \%$ & 34 & $33.7 \%$ \\
\hline
\end{tabular}




\begin{tabular}{|c|c|c|c|c|c|}
\hline (1) & (2) & (3) & (4) & (5) & (6) \\
\hline & $\mathrm{N} / \mathrm{A}$ & 27 & $46.6 \%$ & 22 & $21.8 \%$ \\
\hline \multirow[t]{3}{*}{ Jumlah Pelaku } & Tunggal & 47 & $81.0 \%$ & 93 & $92.1 \%$ \\
\hline & Lebih dari satu & 7 & $12.1 \%$ & 8 & $7.9 \%$ \\
\hline & $\mathrm{N} / \mathrm{A}$ & 4 & $6.9 \%$ & 0 & $0.0 \%$ \\
\hline \multirow[t]{3}{*}{ Hubungan dengan Pelaku } & Dikenal & 48 & $82.8 \%$ & 92 & $91.1 \%$ \\
\hline & Tidak Dikenal & 4 & $6.9 \%$ & 9 & $8.9 \%$ \\
\hline & $\mathrm{N} / \mathrm{A}$ & 6 & $10.3 \%$ & 0 & $0.0 \%$ \\
\hline \multirow[t]{3}{*}{ Waktu Kejadian } & Siang (06.00-17.59 WIB) & 29 & $50.0 \%$ & 52 & $51.5 \%$ \\
\hline & Malam (18.00-05.59 WIB) & 20 & $34.5 \%$ & 39 & $38.6 \%$ \\
\hline & N/A & 9 & $15.5 \%$ & 10 & $9.9 \%$ \\
\hline \multirow[t]{4}{*}{ Tempat Kejadian } & $\begin{array}{l}\text { Tempat Pribadi (rumah, } \\
\text { dll) }\end{array}$ & 36 & $62.1 \%$ & 64 & $63.4 \%$ \\
\hline & Tempat Umum & 16 & $27.6 \%$ & 28 & $27.7 \%$ \\
\hline & Lainnya & 1 & $1.7 \%$ & 6 & $5.9 \%$ \\
\hline & $\mathrm{N} / \mathrm{A}$ & 5 & $8.6 \%$ & 3 & $3.0 \%$ \\
\hline \multirow[t]{8}{*}{ Jenis Penetrasi } & Oral & 2 & $3.4 \%$ & 1 & $1.0 \%$ \\
\hline & Vagina & 42 & $72.4 \%$ & 73 & $72.3 \%$ \\
\hline & Anus & 6 & $10.3 \%$ & 7 & $6.9 \%$ \\
\hline & Oral dan Vagina & 1 & $1.7 \%$ & 11 & $10.9 \%$ \\
\hline & Vagina dan Anus & 0 & $0.0 \%$ & 4 & $4.0 \%$ \\
\hline & Oral dan Anus & 0 & $0.0 \%$ & 1 & $1.0 \%$ \\
\hline & Vagina, Oral, Anus & 0 & $0.0 \%$ & 2 & $2.0 \%$ \\
\hline & $\mathrm{N} / \mathrm{A}$ & 7 & $12.1 \%$ & 2 & $2.0 \%$ \\
\hline Rentang Waktu Kejadian & $<1$ Hari & 15 & $25.9 \%$ & 17 & $16.8 \%$ \\
\hline Kekerasan dengan Waktu & 1 Hari - 1 Minggu & 22 & $37.9 \%$ & 33 & $32.7 \%$ \\
\hline \multirow[t]{3}{*}{ Pemeriksaan } & $>1$ Minggu - 1 Bulan & 8 & $13.8 \%$ & 21 & $20.8 \%$ \\
\hline & $>1$ Bulan & 12 & $20.7 \%$ & 28 & $27.7 \%$ \\
\hline & $\mathrm{N} / \mathrm{A}$ & 1 & $1.7 \%$ & 2 & $2.0 \%$ \\
\hline \multirow{3}{*}{$\begin{array}{l}\text { Riwayat Penggunaan Obat- } \\
\text { obatan/Alkohol }\end{array}$} & Ada & 10 & $17.2 \%$ & 6 & $5.9 \%$ \\
\hline & Tidak ada & 5 & $8.6 \%$ & 68 & $67.3 \%$ \\
\hline & $\mathrm{N} / \mathrm{A}$ & 43 & $74.1 \%$ & 27 & $26.7 \%$ \\
\hline Tanda Kekerasan pada & Ada & 11 & $19.0 \%$ & 13 & $12.9 \%$ \\
\hline \multirow[t]{2}{*}{ Pemeriksaan Fisik Umum } & Tidak ada & 45 & $77.6 \%$ & 88 & $87.1 \%$ \\
\hline & $\mathrm{N} / \mathrm{A}$ & 2 & $3.4 \%$ & 0 & $0.0 \%$ \\
\hline \multirow[t]{3}{*}{ Kelainan pada Anogenital } & Ada & 45 & $77.6 \%$ & 85 & $84.2 \%$ \\
\hline & Tidak ada & 12 & $20.7 \%$ & 16 & $15.8 \%$ \\
\hline & $\mathrm{N} / \mathrm{A}$ & 1 & $1.7 \%$ & 0 & $0.0 \%$ \\
\hline Pemeriksaan & Dilakukan & 41 & $70.7 \%$ & 33 & $32.7 \%$ \\
\hline Sperma/Cairan Mani & Tidak dilakukan & 17 & $29.3 \%$ & 68 & $67.3 \%$ \\
\hline
\end{tabular}

\section{PEMBAHASAN}

Hasil penelitian ini menunjukkan bahwa karakteristik pasien/korban dugaan kekerasan seksual di RSUP Dr. Hasan Sadikin dan RSUP Dr. M. Djamil didominasi oleh perempuan, dengan pelaku tunggal yang dikenal oleh korban dan berlangsung di tempat pribadi. Hal ini sesuai dengan beberapa penelitian terhadap korban kekerasan seksual di Australia $^{9,}$, serta karakteristik korban di Jawa Timur. ${ }^{11}$ Data
Komisi Nasional Anti Perempuan (Komnas Perempuan) juga menyebutkan bahwa pelaku kekerasan seksual terbanyak adalah orang yang dikenal korban, misalnya pacar, ayah kandung/tiri/angkat, dan tetangga. ${ }^{6}$

Usia korban kekerasan seksual di Jawa Barat dan Sumatera Barat lebih banyak dialami oleh anakanak dan remaja, yakni pada terutama kelompok usia 10-19 tahun. Hal ini juga menggambarkan karakteristik 
korban kekerasan seksual di Dumai yaitu usia 0-18 tahun) dan di Aceh yaitu pada usia 5-15 tahun diikuti kelompok usia 15-24 tahun. $^{12,13} \mathrm{Hal}$ ini berlawanan dengan penelitian Sie Ariawan Samatha et al di Semarang yang menyimpulkan bahwa pada tahun 2015-2016, korban terbanyak berusia di atas 18 tahun. $^{14}$ Menurut Karnaji (2017), kecenderungan korban kekerasan seksual masih berusia sangat muda dikaitkan dengan kerentanan mental korban yang lebih mudah diberikan ancaman, paksaan maupun bujuk rayu. ${ }^{11}$ Anak-anak sering kali tidak memiliki keberanian untuk menolak, terutama ketika pelaku adalah orang yang dikenalnya. Hal ini menyebabkan potensi kekerasan seksual lebih besar terjadi pada kelompok usia anak-anak dibandingkan usia dewasa. ${ }^{15}$

Jika dibandingkan dengan penelitian Renate R. Zilkens et al (2017), sebagian besar korban diperiksa dalam rentang waktu kurang dari 24 jam setelah kejadian kekerasan seksual. ${ }^{9}$ Hal ini menunjukkan bahwa korban kekerasan seksual yang diperiksa di RSUP Dr. Hasan Sadikin dan RSUP Dr. M. Djamil cenderung tidak segera melaporkan kekerasan seksual yang dialaminya, sehingga pemeriksaan terbanyak baru dilakukan pada rentang satu hari hingga satu minggu setelah kekerasan seksual. Keterlambatan korban melaporkan kejadian kekerasan seksual yang dialaminya dapat menghilangkan kesempatan menemukan bukti saat pemeriksaan medis, yang diperlukan untuk proses penuntutan pelaku kekerasan seksual. ${ }^{16}$ Penyebab utama korban kekerasan seksual tidak atau terlambat melapor adalah adanya stigma buruk (dikucilkan) masyarakat terhadap korban kekerasan seksual dan rasa malu korban dalam menceritakan kejadian kekerasan seksual yang dialaminya. ${ }^{17,18}$

Korban kekerasan seksual memiliki risiko tinggi menderita gangguan psikologis, seperti gangguan stress pasca trauma, depresi, kecemasan, ide bunuh diri, atau bahkan menjadi pelaku kriminal di kemudian hari. $^{16,19}$ Pada penelitian ini terlihat bahwa $32,8 \%$ korban kekerasan seksual yang diperiksa di RSUP Dr. Hasan Sadikin dan 8,9\% korban kekerasan seksual yang diperiksa di RSUP Dr. M.Djamil mengalami gangguan kejiwaan pasca trauma. Penanganan korban kekerasan seksual harus dilakukan secara multidisiplin, mencakup unsur medis (dokter, psikiater, perawat) dan non medis (psikolog, polisi dan LSM), sehingga kebutuhan medis, psikososial dan medikolegal korban kekerasan seksual dapat terpenuhi secara komprehensif. ${ }^{20}$

Data penelitian ini juga menunjukkan bahwa kekerasan seksual yang dialami korban terutama terjadi pada siang hari $(06.00-17.59 \mathrm{WIB})$. Hal ini berbeda dengan data kekerasan seksual di Jerman oleh Fryszer (2020) yang menyebutkan bahwa 60\% kekerasan seksual terjadi pada malam hari. ${ }^{21}$

Sebagian besar korban kekerasan seksual di RSUP Dr. Hasan Sadikin dan RSUP Dr. M. Djamil hanya mengalami penetrasi melalui vagina, namun data pada Tabel 1 menunjukkan bahwa ada korban yang juga mengalami penetrasi anus dan oral. Selain itu, sebagian kecil korban juga mengalami kekerasan pada bagian tubuh lainnya. Informasi ini sangat mendukung panduan WHO terkait pemeriksaan fisik pada korban kekerasan seksual bahwa pemeriksaan korban harus dilakukan mulai dari kepala hingga ujung kaki, tidak terbatas pada daerah anogenital saja. ${ }^{3}$

\section{SIMPULAN}

Penelitian ini menunjukkan terdapat kesamaan karakteristik kasus kekerasan seksual di Jawa Barat dan Sumatera Barat. Perbedaan yang menonjol terletak pada tingkat pendidikan terakhir korban, dimana korban kekerasan seksual di Sumatera Barat memiliki tingkat pendidikan yang lebih rendah dibandingkan korban kekerasan seksual di Sumatera Barat.

Kekerasan seksual memiliki dampak yang sangat besar pada kesehatan korban kekerasan seksual. Pengetahuan tentang karakteristik kasus kekerasan seksual sangat diperlukan bagi layanan kesehatan untuk dapat memberikan layanan kesehatan yang optimal terhadap korban kekerasan seksual serta dalam upaya preventif kekerasan seksual. Karakteristik kekerasan seksual pada penelitian ini dengan mengambil data dari RS tipe A diharapkan dapat mewakili karakteristik kasus kekerasan seksual di Jawa Barat dan Sumatera Barat. 


\section{UCAPAN TERIMA KASIH}

Terima kasih kepada RSUP Dr. Hasan Sadikin dan RSUP Dr. M. Djamil yang telah mendukung terlaksananya penelitian ini.

\section{DAFTAR PUSTAKA}

1. Kementerian Kesehatan RI. Keputusan Menteri Kesehatan Republik Indonesia Nomor 1226/Menkes/SK/XII/2009 tentang pedoman penatalaksanaan pelayanan terpadu korban kekerasan terhadap perempuan dan anak di rumah sakit. Jakarta: Kementerian Kesehatan RI.

2. Noviana I. Kekerasan seksual terhadap anak: dampak dan penanganannya. Sosio Informa. 2015; 01(01):13-28.

3. World Health Organization (WHO). Guidelines for medico-legal care for victims of sexual violence. Geneva: WHO; 2003. hlm.1-93.

4. Mardina R. Kekerasan terhadap anak dan remaja: Pusat Data dan Informasi Kementerian Kesehatan $\mathrm{RI} ; 2019$.

5. CNN Indonesia. Menguak data jumlah kekerasan perempuan tahun ke tahun. 2018 [diunduh 28 Juli 2019]. Tersedia dari: https://www.cnnindonesia. com/gaya-hidup/20181126110630-284-349231/ menguak-data-jumlah-kekerasan-perempuantahun-ke-tahun

6. Komisi Nasional Anti Kekerasan terhadap Perempuan. Catatan kekerasan terhadap perempuan tahun 2019: kekerasan meningkat kebijakan penghapusan kekerasan seksual untuk membangun ruang aman bagi perempuan dan anak perempuan. Jakarta: Komisi Nasional Anti Kekerasan terhadap Perempuan; 2020.

7. World Health Organization (WHO). Responding to intimate partner violence and sexual violence against women: WHO clinical and policy guidelines: Geneva: WHO; 2013.

8. World Health Organization (WHO). The economic dimensions of interpersonal violence. In: Prevention DolaV, editor. Geneva, Switzerland: WHO; 2004.

9. Zilkens RR, Smith DA, Kelly MC, Mukhtar SA, Semmens JB, Philips MA. Sexual assault and general body injuries: a detailed cross-sectional
Australian Study of 1163 women. Forensic Science International. 2017;279:112-20.

10. Rowse J, Bolt C, Gaya S. Swipe right: the emergence of dating-app facilitatted sexual assault. a descriptive retrospective audit of forensic examination caseload in an Australian Metropolitan service. Forensic Science, Medicine and Pathology. 2020;16:71-7.

11. Karnaji. Perkosaan anak perempuan: pelaku dan pola kejadian. Jurnal Masyarakat, Kebudayaan dan Politik. 2017;30(1):76-83.

12. Albin I, Zubir. Karakteristik Kasus Kekerasan Seksual pada Perempuan di BLUD Rumah Sakit Cut Meutia Berdasarkan Visum et Repertum Periode Tahun 2018. Jurnal Averrous 2020;6(1):59-70.

13. Indrayana MT. Profil kasus kekerasan seksual terhadap perempuan dan anak yang diperiksa di rumah sakit Bhayangkara Dumai (2019-2013). Jurnal Kesehatan Melayu. 2017;1(1).

14. Samatha SA, Dhanardhono T, Bhima SKL. Aspek medis pada kasus kejahatan seksual. Jurnal Kedokteran Diponegoro. 2018;7(2).

15. Humaira DB, Rohmah N, Rifanda N, Novitasari K, Diena UH, Nuqul FL. Kekerasan seksual pada anak: telaah relasi pelaku korban dan kerentanan pada anak. Jurnal Psikoislamika. 2015;12(2):5-10.

16. Trotman GE, Young-Anderson C, Deye KP. Acute sexual assault in the pediatric and adolescent population. Journal of Pediatric and Adolesc Gynecology. 2016;29:518-26.

17. Noviani UZ, Arifah R, Cecep, Humaedi S. Mengatasi dan mencegah tindak kekerasan seksual pada perempuan dengan pelatihan asertif. Jurnal Penelitian \& PKM. 2018;5(1):1-10.

18. Amalia M. Kejahatan kekerasan seksual (perkosaan) terhadap anak dampak dan penanganannya di wilayah hukum Kabupaten Cianjur. Jurnal Mimbar Justitia. 2016;2(1):648-67.

19. Young-Wolff KC, Sarovar V, Klebaner D, Chi F, McCaw B. Changes in psychiatric and medical conditions and healthcare utilization following a diagnosis of sexual assault: A restrospective cohort study. Med Care. 2018;56(8):649-57. 
20. Kementerian Pemberdayaan Perempuan dan Perlindungan Anak Republik Indonesia. Prosedur standar operasional pelaksanaan standar minimal (SPM) bidang layanan terpadu bagi perempuan dan anak korban kekerasan. Jakarta: Kementerian Pemberdayaan Perempuan dan Perlindungan Anak Republik Indonesia; 2010.
21. Fryszer LA, Hoffmann-Walbeck $H$, Etzold $S$, Mockel M, Sehouli J, David M. Sexually assaulted women: result of a retrospective analysis of 850 women in Germany. European Journal of Obstetric \& Ginecology and Reproductive Biology. 2020:11723. 